\title{
Comparison between Two Different Design Concepts of 4- Implant Assisted Mandibular Complete Overdenture: - periimplant bone height changes
}

\author{
${ }^{1}$ Mohammed M Fouad. ${ }^{2}$ Radwa M. K. Emera, ${ }^{3}$ Fatma A El waseef , ${ }^{4}$ Ekhlas A. A. El-Shargaby \\ ${ }^{1}$ BDS, MSc, Phd
}

Professor of Removable Prosthodontics, Faculty of Dentistry, Mansoura University, Mansoura, Egypt

${ }^{2}$ BDS, MSc, Phd

Associate professor of Removable Prosthodontics, Faculty of Dentistry, Mansoura University, Mansoura,

Egypt
${ }^{3}$ BDS, MSc, Phd
Associate professor of Removable Prosthodontics, Faculty of Dentistry, Mansoura University, Mansoura,
Egypt
${ }^{4}$ BDS, MSc
External Residence of Removable Prosthodontics, Faculty of Dentistry, Mansoura University, Mansoura,

Egypt

\begin{abstract}
:
Purpose: This comparative study was done to evaluate, radiographically, the peri-implant bone height changes when using two axial canine implants with either two short first molar implants or two premolar inclined implants for assisting mandibular complete overdenture.
\end{abstract}

Materials and methods: Ten healthy completely edentulous male patients were selected for this study. For each patient, a conventional complete denture was constructed and delivered, then followed up weekly for one month for correction of any complaints. According to the two design concepts of the 4-implant overdenture used in this study, the patients were randomly classified into two equal groups: group [A] had two vertical canine implants with two axial $1^{\text {st }}$ molar short implants (short design concept), and group [B] had two vertical canine implants with two premolar inclined implants (inclined design concept). Each mandibular denture was duplicated to be used as a radiographic stent, then the CBCT surgical guide template was printed according to each design concept of 4 -implant overdenture. These CBCT surgical guide templates were used for installing the implants following the two stage surgical technique and delayed loading protocol. Radiographic vertical and horizontal bone height changes evaluations were performed immediately (T0), 6 months (T6), and 12 months (T12) respectively after picking up of the O-ring ball attachments.

Result: The result of this study showed that the marginal bone loss around all implants in the two groups after one year of loading was within the accepted limits of implant success (less than $1.5 \mathrm{~mm}$ ). Also, these results showed a significant decrease in marginal bone loss (horizontal and vertical) around all implants in both groups during the $2^{\text {nd }} 6$ months after loading except the HBL around the inclined implants in group B which was insignificantly decreased. When comparing anterior and posterior implants in each group during the year of the study, posterior implants showed higher bone loss (VBL and HBL) than anterior implants (significant in group B and non-significant in group A). Although the VBL around inclined implants (in B) was significantly higher than that around short implants (in A) the HBL around short implants (of group A) was significantly higher than that around inclined implants (of group B) after one year of loading. 
Conclusion: From the results of this study, it could be concluded that: 1- In regard to the accepted limits of peri-implant bone loss, two axial canine implants with either $1^{\text {st }}$ molar short implant or premolar inclined implant design concepts can be used for assisting the mandibular complete overdentures. 2- The posterior short implant concept can be considered more promising design than inclined implant concept when designing the 4-implant assisted mandibular complete overdenture, regarding the preservation of periimplant alveolar bone height. 3- Using of bilateral posterior implants preserve the alveolar bone around the anterior implants used for assisting mandibular overdenture.

Keywords: Short implant concept, inclined implant concept, O-ring ball attachment, 4-implant assisted overdenture.

\section{Introduction}

In mandibular alveolar ridge, placement of conventional long implants is hindered by severely resorbed alveolar ridges due to anatomical vital structures limitations such as the mental foramen, inferior alveolar nerve, mandibular canal and shape of the ridge. ${ }^{(1)}$ An extensive surgical bone augmentation procedure is often necessary to achieve sufficient bone support to place standard implants in the posterior mandible. Augmentation surgery carriers a higher risk of patient morbidity and complications as well as higher costs and longer time intervals to complete the treatment. To avoid grafting procedures and to utilize preexisting bone in the most effective way, angled implants is a well-documented alternative, with no apparent clinically significant difference in success rates compared with axially placed implants. One particular treatment option is marketed as the All-on-4 treatment concept. ${ }^{(2)}$ If there is no enough quantity bone utilizing to All-on-4 treatment concept, Short implants have been proposed also as an alternative to the long ones in an attempt to avoid some surgical procedures such as bone grafting. In addition, they also reduce the morbidity, treatment time, costs and complications rates. ${ }^{(3)}$ Short implant is simple, cost effective and highly predictable. In particular, practitioners want to rehabilitate most patients without implementing advanced surgical techniques, such as alveolar augmentations. ${ }^{(4)}$

Some studies have shown positive results for short implants, even for those shorter than $7 \mathrm{~mm}$ in length. Higher implant failure and more complications have been reported for patients undergoing bone graft, to receive long implants, when compared to those receiving short implants only. In 20-year follow up study, no implant fractures or complications have been found for short implants. ${ }^{(3)}$

Finally, Placement of short implants less than $8 \mathrm{~mm}$ long may be considered an effective option to rehabilitate edentulous patients whenever conventional implants cannot be placed without prior bone augmentation procedures, such as autologous bone graft, osteogenic distraction or mental foramen transposition, which increase surgical morbidity and treatment time. ${ }^{(5)}$

\section{Material and Method}

For ten Completely edentulous male patients insertion of conventional maxillary and mandibular complete dentures (Fig.1a and b) after patient selection according to Inclusion criteria as, all the Patients free from any systemic disease or factors that relatively or locally contraindicated for dental implantation, specially the diseases that relating to bone resorption, Patients with available inter-arch space not less than (10mm$12 \mathrm{~mm}$ ) that allows of the mandibular overdenture with ball attachments, and Exclusion criteria as History of previous parafunctional habits (bruxism, clenching), TMD, and Patients that absolutely contraindicated for surgical implantation (uncontrolled bleeding disorders, hepatitis or cardiac patients) or patients under radiotherapy, chemotherapy, immunosuppresses or anticoagulants drugs, and According to the two design concepts with 4-implnts, all patients were divided into two equal groups:

Group A (short design concept): in which Two vertical implants were inserted in the canine areas $(13 \mathrm{~mm}$ length $\times 3.7 \mathrm{~mm}$ diameter) and two short vertical implants were inserted in the 1 st molar area $(6 \mathrm{~mm}$ length $\times$ $4.3 \mathrm{~mm}$ diameter).

Group B (inclined design concept):Two vertical implants were inserted in the canine areas (13mm length $\times$ $3.7 \mathrm{~mm}$ diameter) and two 300 distally inclined implants were inserted in the second premolar area $(13 \mathrm{~mm}$ length $\times 3.7 \mathrm{~mm}$ diameter). 


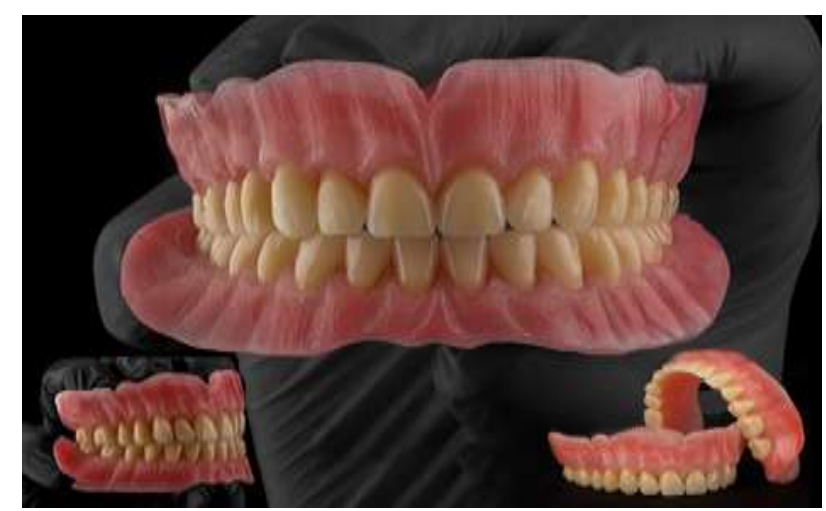

(Fig.1a and b) Finishing and polishing dentures

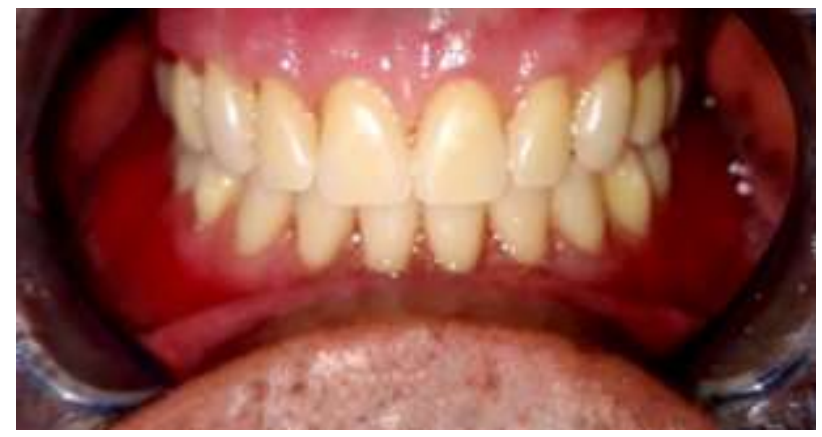

(Fig.1b) Complete denture insertion.

Stereolithographic surgical guide template fixation (Fig.3): the Stereolithographic mandibular surgical guide stent was fabricated according to De Kok et al. ${ }^{(6)}$ by mandibular denture duplication using clear heat cure clear acrylic material. Double CBCT scan was done to the duplicated denture. One of them performed inside the patient's mouth during wearing it in centric occlusion position, whereas the other scan was performed outside the patient's mouth then Superimposition of the dual scan were done guided by radiopaque markers using the computer software to create 3D image for prospective implant locations and angulations planning. Rapid prototyping machine was used for construction of stereolithographic stent fix in patient mouth during surgery.

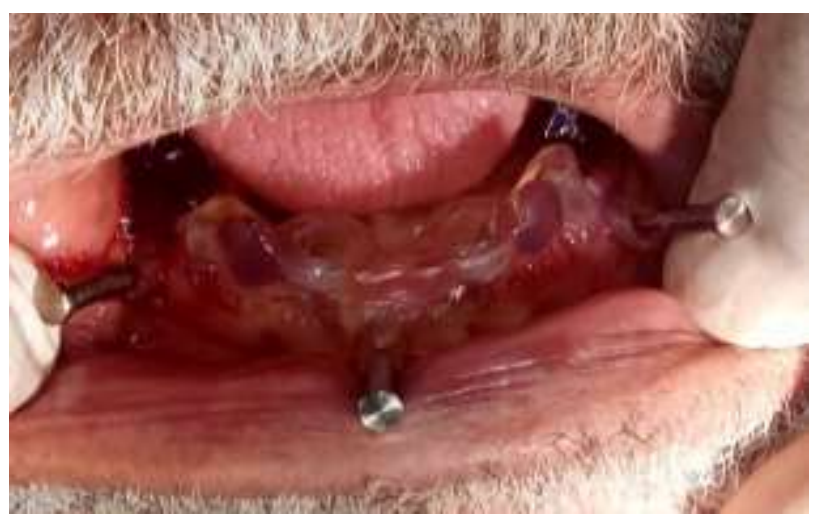

(Fig.3) Stereolithographic Fixation.

Surgical procedures (Fig.4): after local anesthesia surgical template was fixed on the mandibular ridge by fixation pins, tissue punch was used to cut down the gingival tissue on the crest of the ridge in the prospective sites of the 4 implants, osteotomy was prepared with Initial drill then, Serial drilling by the larger size drills, and followed by successive drills to reach the final drill, and Preparation of the areas to receive the implants. 


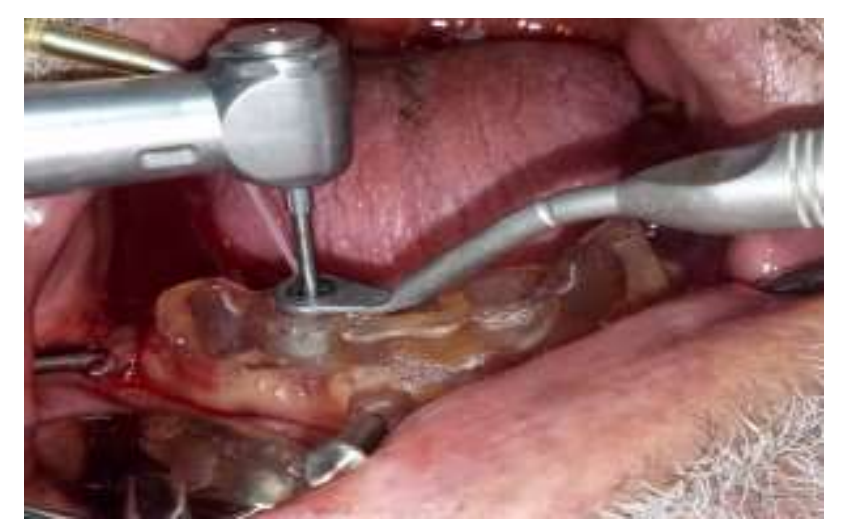

(Fig.4): Osteotomy was done.

With the manual adaptor, two short implants were inserted axially in both first molar areas, and two implants were also axially inserted the canine areas of both side (for short design) and, two implants were inserted with $30^{\circ}$ distal inclination in both first premolar areas, and two implants were also axially inserted the canine areas of both side (for inclined design) (Fig.5)

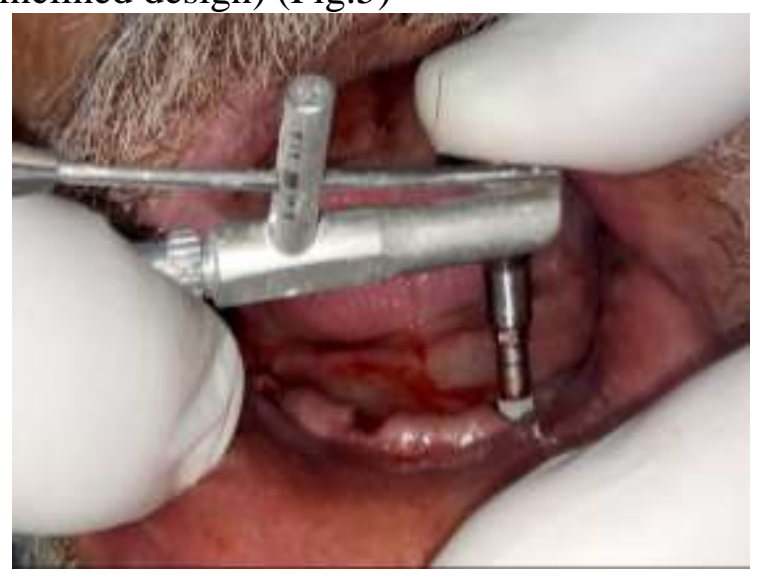

(Fig.5) screwing the implant

Panoramic x-ray was made for each patient to verify the predetermined parallelism and location of implants for both group, short design group (group A) (Fig.6) and inclined design group (group B) (Fig.7).

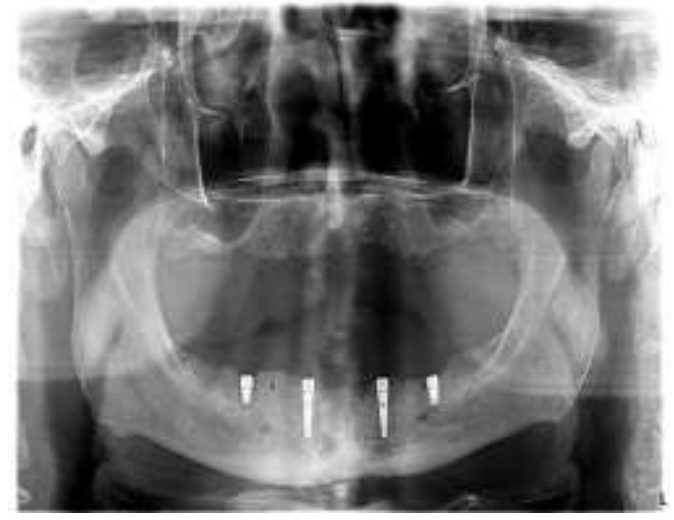

(Fig.6) group A

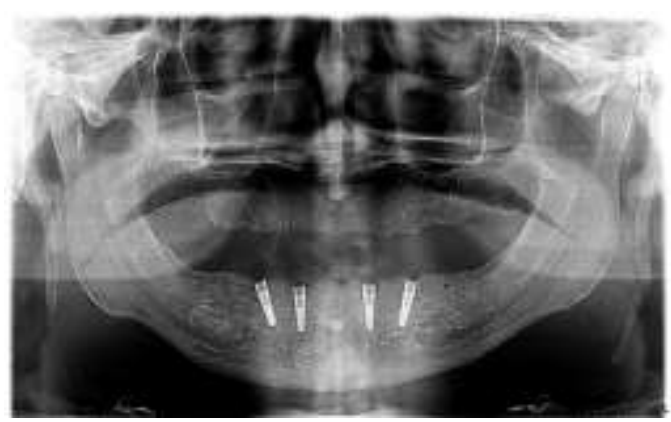


(Fig.7) group B

Pick up procedures: Direct pick up technique was carried out according to Taddei et al. ${ }^{(7)}$ after healing abutments were unscrewed from the implant fixture and ball attachments were screwed in their implant fixtures and the female housing were placed over the ball attachments (Fig.8), and in the dough stage the auto polymerizing acrylic resin was placed inside a rubber syringe, while the patient occluded in centric position, an appropriate quantity of the material in the labial vent was injected. After curing of the acrylic resin, the denture was removed, finished and polished. (Fig. 9)

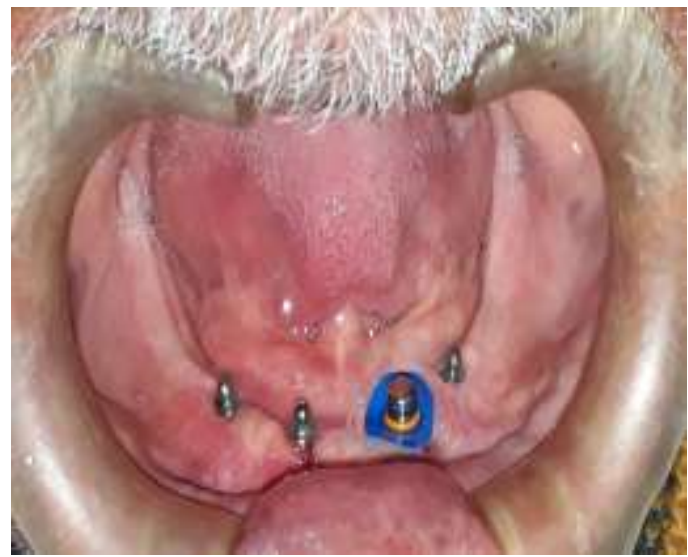

(Fig.8) Female housing with O.T ring.

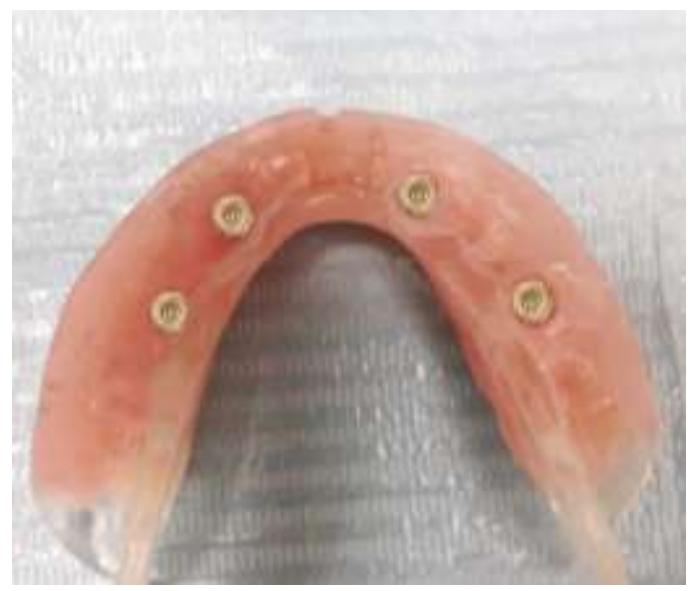

(Fig.9) Intaglio of overdenture.

The evaluation of the study accomplished by standardized the film positioning image distances, digital periapical intraoral film with film positioning system (Fig. 10) were used. The evaluation was conducted with occlusal acrylic index immediately on the day of the pick up and overdenture loading (T0), six months later (T6) and after 12 months (T12) respectively according to Abdel-Khalek ${ }^{(8)}$

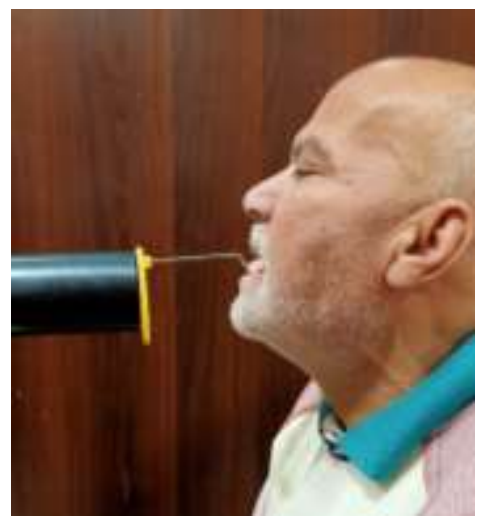

(Fig.10) standardized the film positioning 
Evaluation of the periapical VBL from the digital computer software program, and for all the implant fixtures, mesial and distal bone height level were measured by a length calibration tool that applied to create the most coronal margin point of the implant collar, (reference point $A$ ) and the most coronal bone margin point to implant contact (point B). Digitally the software draws the vertical mesial line (AB) on alveolar bone (Fig.11). The vertical distance between point (A) and point (B) mesially and distally was recorded to the nearest $\mathrm{mm}(0.01 \mathrm{~mm})$ as a digital reading to the mesial and distal levels or changes of bone high to the implants. subtracting $\mathrm{AB}$ line length (mesially and distally) at (T12) from AB line length at (T0). Also, subtracting $A B$ line length (mesially and distally) at (T6) from $A B$ line length at (T0). All calculation were performed to create the alveolar bone height changes mesially and distally for each implant fixture as in study of Emera et al. ${ }^{(9)}$

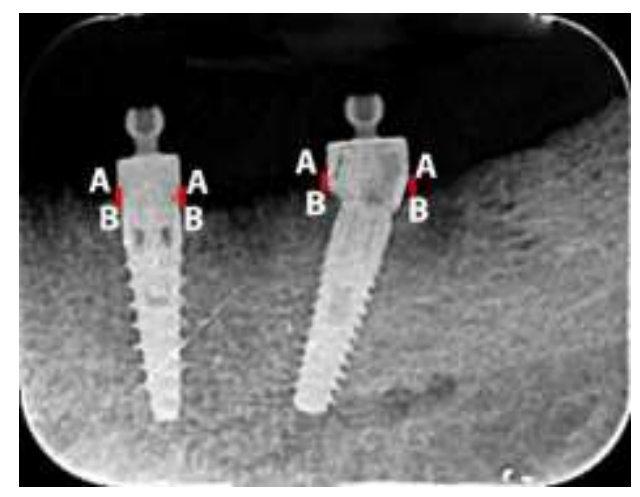

(Fig.11) VBL measurements.

Evaluation of the periapical HBL was from the digital computer software program, and for all the implant fixtures, mesial and distal bone height level were measured by a length calibration tool that applied to the distance from implant long axis (line which bisecting the implant) and (point $\mathrm{C}$ ) which is the intersecting point of the tangent to the crater-shaped defect (CB line) and the tangent to the horizontal bony crest $(\mathrm{CD}$ line) was estimated and denoted as the horizontal bone level. To measure HBL the horizontal bone level at T0 was subtracted from that at T6 and T12.The peri-implant alveolar HBL was measured in mm. (Fig.12) as in study of Emera et al. ${ }^{(9)}$

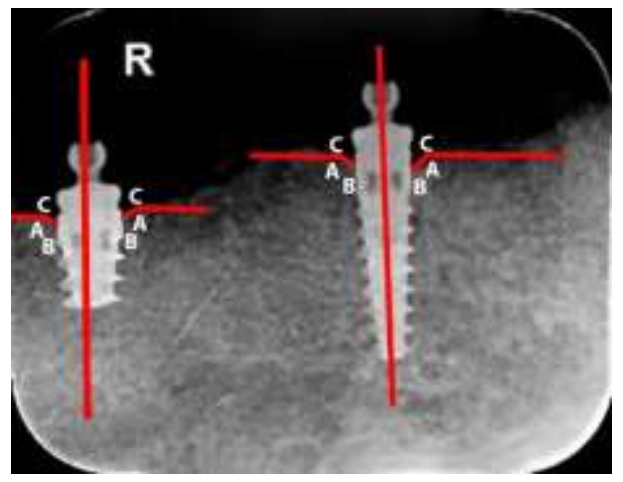

(Fig.12) HBL measurements.

\section{Results}

A-Comparison of VBL between groups for all implants: VBL decrease significantly with advance of time in both groups, inclined implant group (B) showed significant higher total VBL than short implant group (A) at the intervals T0-T6 and T0-12.

Table 1: Comparison of VBL of all implants between groups and observation times

\begin{tabular}{|c|c|c|c|c|c|}
\hline & & T0_T6 & T6_T12 & T0_T12 & $\begin{array}{c}\text { Repeated } \\
\text { Measures } \\
\text { ANOVA } \\
\text { P value }\end{array}$ \\
\hline \multirow{2}{*}{$\begin{array}{c}\mathrm{X} \pm \mathrm{SD} \\
(\text { group A) }\end{array}$} & & $0.64 \pm 25$ & $0.45 \pm 21$ & $1.09 \pm 21$ & \multirow{2}{*}{$<0.001 *$} \\
\hline & Paired t-test & \multicolumn{2}{|c|}{$<0.014 *$} & & \\
\hline
\end{tabular}




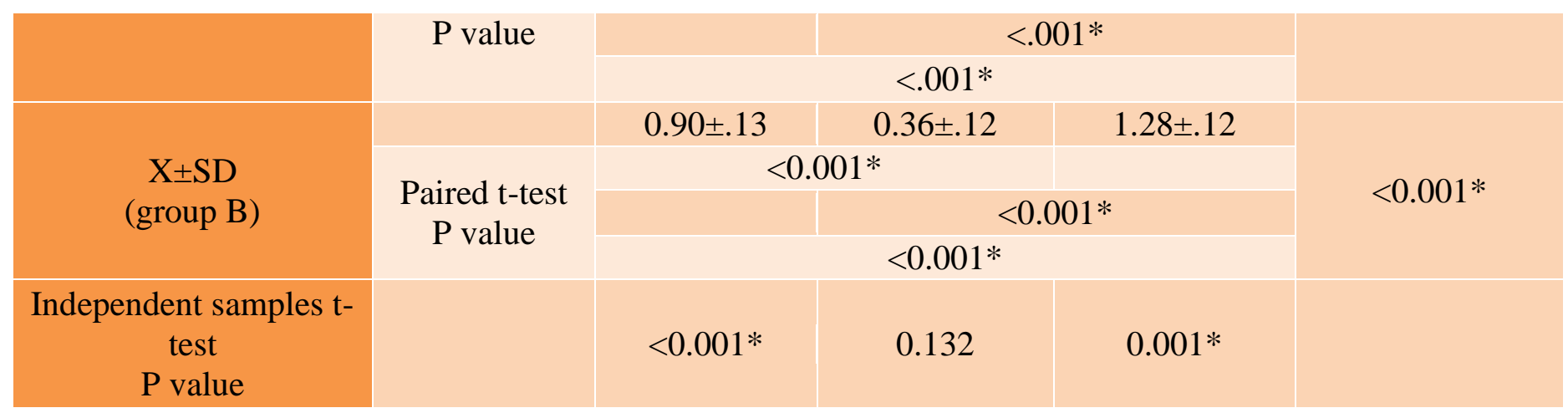

$\mathrm{X}=$ mean, $\mathrm{SD}=$ standard deviation, $* \mathrm{p}$ is significant at $5 \%$ level

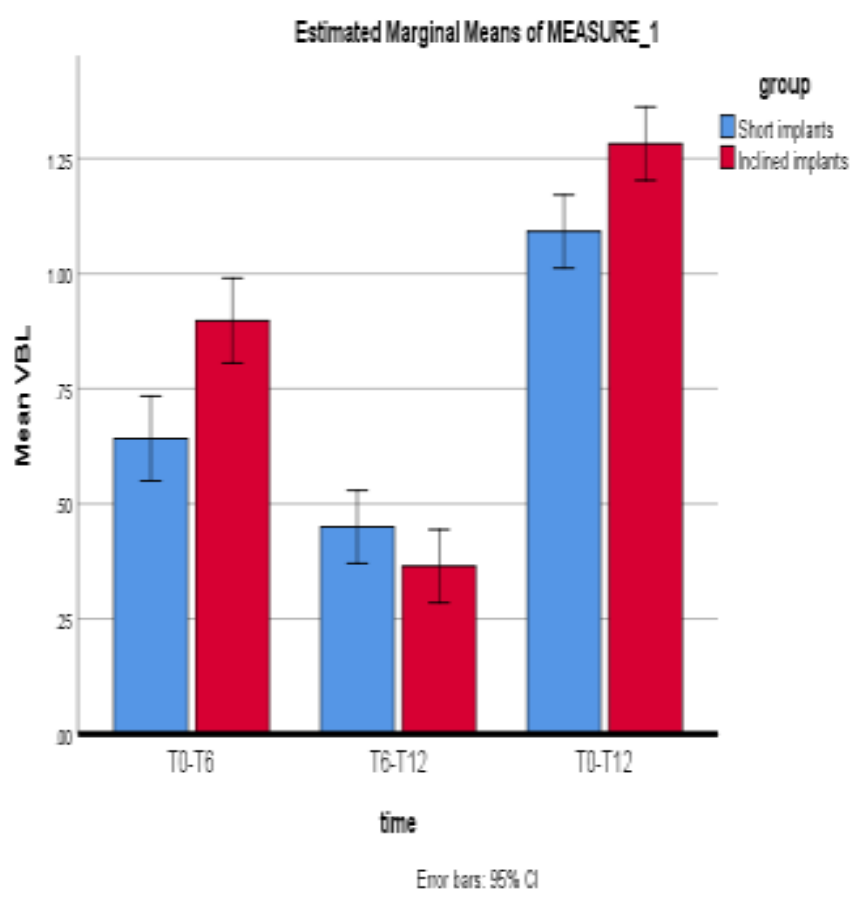

(Fig.13) Comparison of mean VBL of all implants between groups at different observation times

B-Comparison of HBL between groups for all implants: HBL decreased significantly with advance of time in both groups, Short implant group showed significant higher total HBL than inclined group at the interval T0-T6 and T0-T12. No significant difference between groups was noted at T6-T12.

Table 2: Comparison of total HBL of all implants between groups and observation times

\begin{tabular}{|c|c|c|c|c|c|}
\hline & & T0_T6 & T6_T12 & T0_T12 & $\begin{array}{c}\text { Repeated } \\
\text { Measures } \\
\text { ANOVA } \\
\text { P value }\end{array}$ \\
\hline \multirow{4}{*}{$\begin{array}{c}\text { X } \pm \text { SD } \\
(\text { Group A) }\end{array}$} & \multirow{4}{*}{$\begin{array}{l}\text { Paired t-test } \\
P \text { value }\end{array}$} & $0.58 \pm .12$ & $0.31 \pm .12$ & $0.90 \pm .19$ & \multirow{4}{*}{$<0.001 *$} \\
\hline & & \multicolumn{2}{|c|}{$<0.001^{*}$} & & \\
\hline & & & \multicolumn{2}{|c|}{$<0.001^{*}$} & \\
\hline & & \multicolumn{3}{|c|}{$<0.001^{*}$} & \\
\hline \multirow{4}{*}{$\begin{array}{c}\mathrm{X} \pm \mathrm{SD} \\
(\text { group B) }\end{array}$} & \multirow{4}{*}{$\begin{array}{c}\text { Paired t-test } \\
\text { P value }\end{array}$} & $0.43 \pm .16$ & $0.32 \pm .09$ & $0.68 \pm .17$ & \multirow{4}{*}{$<0.001^{*}$} \\
\hline & & & & & \\
\hline & & & \multirow{2}{*}{\multicolumn{2}{|c|}{$<0.001 *<0.001 *$}} & \\
\hline & & & & & \\
\hline
\end{tabular}


$\mathrm{X}=$ mean, $\mathrm{SD}=$ standard deviation, $* \mathrm{p}$ is significant at $5 \%$ level

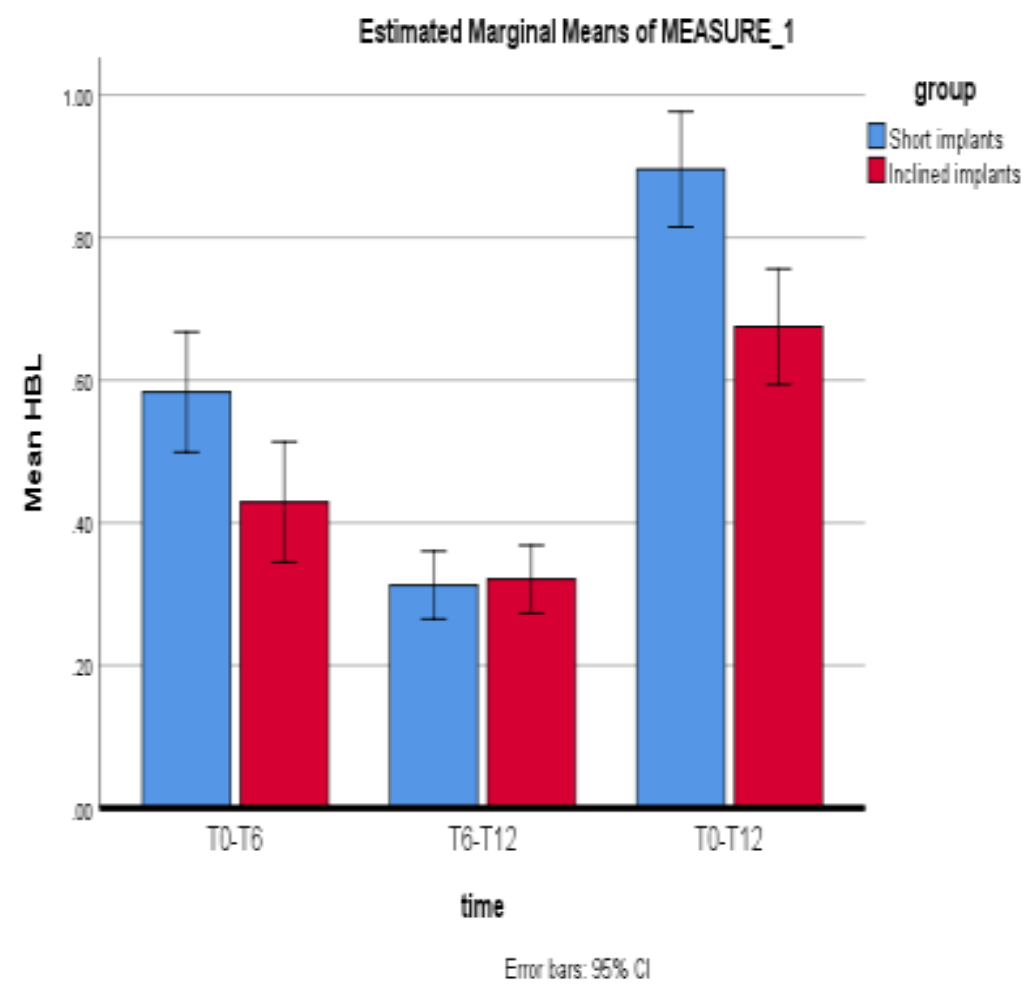

(Fig.14) Comparison of total HBL between groups at different observation times

\section{Discussion}

Placing four implants has provided the clinician with the ability to restore non-ideal ridges. Moreover, mucosal bearing areas and anteriorposterior rocking of the appliance have been reduced. ${ }^{(\mathbf{1 0})}$

The best location of anterior placed implant installation at inter foramina distance is the canine area, while the posterior implant placed in the first molar area.

If there was not available bone quantity, the use of short implants allows treatment of patients who are unable to undergo complex surgical bone augmentation for anatomic or medical reasons. Moreover, the use of short-length implants reduces the, cost and treatment time ${ }^{(\mathbf{1 2})}$

The result of this study showed that the VBL around all implants in the two groups after one year of loading was within the accepted limits of implant success, (less than $1.5 \mathrm{~mm}$ ). This was concurred with the success criteria of dental implants that reported by Albrektsson et al. ${ }^{(13)}$ who stated that marginal VBL in the first year after implant insertion should be less than $1.5 \mathrm{~mm}$ followed by annual bone loss not more than $0.2 \mathrm{~mm}$. The comparison of VBL between groups for all implants found decreased bone loss during the 2nd 6 months after loading, this may duo to maturation of bone that withstand functional forces as strength of the bone increased from the beginning of loading after surgical exposure up to 1 year after loading, where the bone became denser because of increasing the mineral content. This explanation was in agreement with the study performed by Albrektsson et al. ${ }^{\text {(13) }}$ who described this phenomenon as a "steady state" and correlated the decrease of bone loss around dental implants at the end of first year to maturation of bone after implant placement and adaptation of bone to resist functional force.

Also when comparing VBL around anterior and posterior implants between groups, group B posterior implants after one year of loading was found that significant higher VBL than posterior implants in group A. This was in agreement with Chrcanovic et al. ${ }^{(14)}$, they explain this observation could be due to the continued resorption of the residual ridge under the prosthesis, thus may exacerbate the unfavorable loading direction and induces greater bone loss around non axial implants. 
From the other hand, when comparing between HBL around anterior and posterior implants, HBL decreased significantly with advance of time in both groups. The reduced HBL in this study agreement with Elsyad et al. ${ }^{(15)}$ They attributed this loss to the amount of posterior ridge resorption that occurred after 5 years which may mask the HBL.

The same result of this study in regarding to less significant difference was found in Jazza et al. ${ }^{(16)}$ study. They explain this less significant as under functional loading, the stress transmitted to solitary posterior implants of both groups will be damped by female housing of posterior healing abutments leading to close approximation of alveolar bone resorption.

\section{Conclusions:}

1- With regard to the accepted limits of peri-implant bone loss, two axial canine implants with either 1st molar short implant or premolar inclined implant design concepts can be used for assisting the mandibular complete overdentures.

2- The posterior short implant concept can be considered more promising design than inclined implant concept when designing the 4-implant assisted mandibular complete overdenture, regarding the preservation of peri-implant alveolar bone height.

3- Using of bilateral posterior short implants preserve the alveolar bone around the anterior implants used for assisting mandibular overdentures.

\section{Recommendation}

Other studies with longer follow up time and addition to other methods of evaluation are recommended to differentiate between the two studied design concepts.

\section{Acknowledgment}

I would like to thank all of:

ALLAH, by the grace of whom help me to end this project.

Prof. Mohammed M Fouad, thank you so much for your diligence in working on this project. You were always the persons who kept me moving forward and I would not have been able to do it without your guidance. It has been a great pleasure working with you and I will never forget all of your kindness.

Dr. Radwa M. K. Emera, thank you for providing me with the opportunity to study and learn more about dentistry that I could have ever imagined. Thank you for always being positive, helpful and enthusiastic about dentistry.

Dr. Fatma A El waseef, thank you for the years of wisdom, guidance and meticulous training. I will take with me so many wonderful lessons, from you about dentistry and life.

Thanks for all Doctors and nurses in Department of Removable Prosthodontics

Faculty of Dentistry Mansoura University

Thanks for all my friends.

Thanks for my best family

Signature, Ekhlas A A Al- Shargaby.

\section{References}


1. Sultana N, Bartlett DW, Suleiman M. Retention of implant-supported overdentures at different implant angulations: comparing Locator and ball attachments. Clinical Oral Implants Research. 2017;28(11):1406-10.

2. Patzelt SBM, Bahat O, Reynolds MA, Strub JR. The All-on-Four Treatment Concept: A Systematic Review. Clinical Implant Dentistry and Related Research. 2013;16(6):836-55.

3. Pimentel MJ, Silva WJd, Del Bel Cury AA. Short implants to support mandibular complete dentures - photoelastic analysis. Brazilian Oral Research. 2017;31(2):1-10.

4. Van Assche N, Michels S, Quirynen M, Naert I. Extra short dental implants supporting an overdenture in the edentulous maxilla: a proof of concept. Clinical Oral Implants Research. 2011;23(5):567-76.

5. Peixoto HE, Camati PR, Faot F, Sotto-Maior BS, Martinez EF, Peruzzo DC. Rehabilitation of the atrophic mandible with short implants in different positions: A finite elements study. Materials Science and Engineering: C. 2017;80(3):122-8.

6. De Kok IJ, Thalji G, Bryington M, Cooper LF. Radiographic Stents. Dental Clinics of North America. 2014;58(1):181-92.

7. Taddei C, Metz M, Waltman E, Etienne O. Direct procedure for connecting a mandibular implantretained overdenture with ball attachments. The Journal of Prosthetic Dentistry. 2004;92(4):403-4.

8. Abdel-Khalek EA. Fabrication of a Simple Acrylic Template to Standardize Periapical Radiographs for Implants Retaining Mandibular Bar Overdentures. Journal of Prosthodontics. 2017;28(2):e657e60.

9. Emera RMK, Askar OM, Ahmed WS. Two Implants Retained Complete Mandibular Overdenture with Zirconia-PEEK Telescopic Attachment: Radiographic Evaluation of Peri-implant Bone Level Changes. Oral Health Dental Sci. 2020;4(1):1-7.

10. Vogel RC. CE 2-Implant Overdentures: A New Standard of Care for Edentulous Patients--Current Concepts and Techniques. Compendium. 2008;29(5):270-6.

11. Obeid G, Shafie H. S411: Basic Surgical and Prosthetic Aspects of Implant-Supported Overdentures. Journal of Oral and Maxillofacial Surgery. 2007;65(9):101-2.

12. $\mathrm{Xu} \mathrm{X,} \mathrm{Hu} \mathrm{B,} \mathrm{Xu} \mathrm{Y,} \mathrm{Liu} \mathrm{Q,} \mathrm{Ding} \mathrm{H,} \mathrm{Xu} \mathrm{L.} \mathrm{Short} \mathrm{versus} \mathrm{standard} \mathrm{implants} \mathrm{for} \mathrm{single-crown}$ restorations in the posterior region: A systematic review and meta-analysis. The Journal of Prosthetic Dentistry. 2020;2(1):1-3.

13. Albrektsson T, Zarb G, Worthington P, Eriksson A. The long-term efficacy of currently used dental implants: a review and proposed criteria of success. Int j oral maxillofac implants. 1986;1(1):11-25.

14. Chrcanovic BR, Albrektsson T, Wennerberg A. Tilted versus axially placed dental implants: A metaanalysis. Journal of Dentistry. 2015;43(2):149-70. 
15. Elsyad MA, Alokda MM, Gebreel AA, Hammouda NI, Habib AA. Effect of two designs of implantsupported overdentures on peri-implant and posterior mandibular bone resorptions: a 5-year prospective radiographic study. Clinical Oral Implants Research. 2016;28(10):e184-e92.

16. Jazza N, Abdel-Khalik M, El-Gayyar M, Emera R. Stress applied on implant assisting mandibular complete overdenture - in vitro comparison of Casted Metal bar and InFibra Ribbon bar attachments. Mans Jour Os Dent. 2014;1(2):1-6. 